\title{
Donor Heart Preservation with Hydrogen Sulfide: A Systematic Review and Meta-Analysis
}

\author{
Imran A. Ertugrul ${ }^{1}$, Vincent van Suylen ${ }^{1}$, Kevin Damman ${ }^{2}$, Marie-Sophie L. Y. de Koning ${ }^{2}{ }^{(0)}$ \\ Harry van Goor ${ }^{3, *}$ (i) and Michiel E. Erasmus ${ }^{1}$ (i) \\ 1 University Medical Centre Groningen, Department of Cardiothoracic Surgery, University of Groningen, \\ 9700 RB Groningen, The Netherlands; i.a.ertugrul@umcg.nl (I.A.E.); v.van.suylen@umcg.nl (V.v.S.); \\ m.e.erasmus@umcg.nl (M.E.E.) \\ 2 University Medical Centre Groningen, Department of Cardiology, University of Groningen, \\ 9700 RB Groningen, The Netherlands; k.damman@umcg.nl (K.D.); m.s.l.y.de.koning@umcg.nl (M.-S.L.Y.d.K.) \\ 3 University Medical Centre Groningen, Department of Pathology and Medical Biology, \\ University of Groningen, 9700 RB Groningen, The Netherlands \\ * Correspondence: h.van.goor@umcg.nl
}

Citation: Ertugrul, I.A.; van Suylen, V.; Damman, K.; de Koning, M.-S.L.Y.; van Goor, H.; Erasmus, M.E. Donor Heart Preservation with Hydrogen Sulfide: A Systematic Review and Meta-Analysis. Int. J. Mol. Sci. 2021, 22, 5737. https://doi.org/10.3390/ ijms22115737

Academic Editor: Felix B. Engel

Received: 7 April 2021

Accepted: 23 May 2021

Published: 27 May 2021

Publisher's Note: MDPI stays neutral with regard to jurisdictional claims in published maps and institutional affiliations.

Copyright: (c) 2021 by the authors. Licensee MDPI, Basel, Switzerland. This article is an open access article distributed under the terms and conditions of the Creative Commons Attribution (CC BY) license (https:// creativecommons.org/licenses/by/ $4.0 /)$.

\begin{abstract}
Preclinical studies have shown that postconditioning with hydrogen sulfide $\left(\mathrm{H}_{2} \mathrm{~S}\right)$ exerts cardioprotective effects against myocardial ischemia-reperfusion injury (IRI). The aim of this study was to appraise the current evidence of the cardioprotective effects of $\mathrm{H}_{2} \mathrm{~S}$ against IRI in order to explore the future implementation of $\mathrm{H}_{2} \mathrm{~S}$ in clinical cardiac transplantation. The current literature on $\mathrm{H}_{2} \mathrm{~S}$ postconditioning in the setting of global myocardial ischemia was systematically reviewed and analyzed, performing meta-analyses. A literature search of the electronic databases Medline, Embase and Cinahl identified 1835 studies that were subjected to our pre-defined inclusion criteria. Sixteen studies were considered eligible for inclusion. Postconditioning with $\mathrm{H}_{2} \mathrm{~S}$ showed significant robust effects with regard to limiting infarct size (standardized mean difference (SMD) $=-4.12$, $95 \% \mathrm{CI}[-5.53--2.71], p<0.00001)$. Furthermore, $\mathrm{H}_{2} \mathrm{~S}$ postconditioning consistently resulted in a significantly lower release of cardiac injury markers, lower levels of oxidative stress and improved cardiac function. Postconditioning with slow-releasing $\mathrm{H}_{2} \mathrm{~S}$ donors offers a valuable opportunity for novel therapies within cardiac preservation for transplantation. Before clinical implication, studies evaluating the long-term effects of $\mathrm{H}_{2} \mathrm{~S}$ treatment and effects of $\mathrm{H}_{2} \mathrm{~S}$ treatment in large animal studies are warranted.
\end{abstract}

Keywords: hydrogen sulfide; ischemia-reperfusion injury; postconditioning; systematic review; meta-analysis; organ preservation; cardiac transplantation

\section{Introduction}

Cardiac transplantation is the treatment of choice for patients with end-stage heart failure (HF). The global incidence of end-stage HF is rising, while cardiac transplantation is limited by the severe shortage of donor hearts suitable for transplantation [1]. Donation after brain death (DBD) is the current standard for cardiac transplantation. However, in order to enlarge the donor pool, the use of marginal donors and donation after circulatory death (DCD) has gained interest. One of the prominent challenges in cardiac transplantation is myocardial ischemia-reperfusion injury (IRI) to the graft. IRI is the inevitable result of initial restriction of blood supply to the heart followed by subsequent reperfusion. IRI has not only been associated with microvascular dysfunction, arrhythmias and primary graft dysfunction but also with aggravation of tissue damage that has already occurred by circulatory arrest in marginal donors and DCD hearts $[2,3]$.

Static cold storage (CS) is currently the standard method for minimizing IRI during donor heart preservation. Although CS significantly reduces myocardial metabolism, there is a continued metabolism at a lower level, and ischemic damage occurs over time. 
Continuation of anaerobic metabolism results in depletion of adenosine triphosphate stores, followed by acidosis, ionic disturbances, production of reactive oxygen species (ROS), oxidative stress and eventually necrosis. Re-establishment of blood flow restores homeostasis and is essential to salvage ischemic tissues. However, reperfusion can paradoxically result in further tissue damage by a quick $\mathrm{pH}$ change, activation of inflammatory cascades and cell death programs, calcium $\left(\mathrm{Ca}^{2+}\right)$ overload and increased ROS production [4-6]. A maximum period of 4 to $6 \mathrm{~h}$ is currently accepted as a safe ischemic preservation time for DBD hearts. Longer ischemic times have been demonstrated to adversely affect post-transplant survival [7]. CS of DCD hearts is insufficient since these hearts have already sustained extensive ischemic injury due to circulatory arrest [8]. Novel strategies to protect the heart from IRI in order to increase the donor pool have been reported, including pharmacological intervention with hydrogen sulfide $\left(\mathrm{H}_{2} \mathrm{~S}\right)$.

$\mathrm{H}_{2} \mathrm{~S}$ is an endogenously produced gasotransmitter generated by cystathionine $\gamma$-lyase, cystathionine $\beta$-synthase and 3-mercaptopyruvate sulfurtransferase. At high concentrations, gasotransmitters are toxic, but at low concentrations, they function as important signaling molecules [9]. In the cardiovascular system, endogenous $\mathrm{H}_{2} \mathrm{~S}$ plays a prominent role in vasodilatation and blood pressure regulation [10]. Multiple exogenous $\mathrm{H}_{2} \mathrm{~S}$-releasing compounds $\left(\mathrm{H}_{2} \mathrm{~S}\right.$ donors) are available and have been extensively researched in diverse pathological processes, including myocardial IRI [11]. An increasing body of evidence indicates that pre- and postconditioning the heart with an exogenous $\mathrm{H}_{2} \mathrm{~S}$ donor exerts cardioprotective effects by limiting inflammation and oxidative stress, and by protecting against mitochondrial damage and apoptosis caused by IRI [12-14]. In addition, $\mathrm{H}_{2} \mathrm{~S}$ is known to act as a regulator of energy production under stress conditions, which sustains mitochondrial ATP production under hypoxic conditions [15]. These beneficial effects of $\mathrm{H}_{2} \mathrm{~S}$, especially in $\mathrm{H}_{2} \mathrm{~S}$ postconditioning, could be of additional value in treatment of myocardial infarction (local ischemia) and in the setting of cardiac transplantation and donor heart preservation (global ischemia).

Although $\mathrm{H}_{2} \mathrm{~S}$ therapy against IRI has been investigated abundantly in animal studies, no published comprehensive review on postconditioning with $\mathrm{H}_{2} \mathrm{~S}$ in the setting of global ischemia is available. The aim of this study was to appraise the current evidence of the cardioprotective effects of $\mathrm{H}_{2} \mathrm{~S}$ postconditioning against IRI by systematically reviewing the literature and performing meta-analyses, in order to explore the future implementation of $\mathrm{H}_{2} \mathrm{~S}$ in clinical cardiac transplantation.

\section{Results}

\subsection{Study Selection Process}

The initial electronic search identified 1835 studies. After eliminating duplicates, 1078 studies remained. The remaining studies were screened at the title and/or abstract level to check for relevancy to our study scope. Thirty-two studies were considered relevant and full-text reviewed. Finally, 16 studies were included in the analysis (Figure 1).

\subsection{Main Characteristics}

The characteristics of the included studies are summarized in Table 1. All studies were rodent models of IRI (rat $n=14$, mouse $n=2$ ). Sodium hydrosulfide (NaHS) was the most commonly used $\mathrm{H}_{2} \mathrm{~S}$ donor $(n=12)$. Other used $\mathrm{H}_{2} \mathrm{~S}$ donors were sodium thiosulfate (STS) $(n=3)$, GYY4137, DATS-MSN and sodium sulfate $\left(\mathrm{Na}_{2} \mathrm{~S}\right)($ all $n=1)$. The $\mathrm{H}_{2} \mathrm{~S}$ donor was administered in the perfusate of Langendorff perfusion $(n=13)$ or in cold storage solution $(n=3)$. In Langendorff models, four studies used a postconditioning protocol whereby NaHS was applied in multiple rounds for 10-15 s (ischemic postconditioning) [16-19]. Evaluated variables relevant to our study scope are shown in Table 2. The definition of infarct size is the area of necrosis in the myocardial tissue. The method of choice to determine infarct size is by 2,3,5-triphenyltetrazolium (TCC) staining. This method has been shown to reliably identify a necrotic myocardium from a viable myocardium. The viable myocardium is stained red as the water-soluble compound TTC is converted by active mitochondrial 
dehydrogenases into an insoluble red precipitate. The extent of red staining correlates with the number of viable mitochondria and differentiates viable and nonviable tissue. The extent of the area of necrosis is quantified by computerized planimetry [20]. Data regarding inflammation were excluded for meta-analysis since only one study evaluated inflammation (not included in Table 2) [21]. In four of the included studies, multiple intervention groups had the same control group $[17,18,21,22]$. These additional intervention groups were excluded for meta-analyses. Exclusion was based on the least relevant $\mathrm{H}_{2} \mathrm{~S}$ donor type, dosage and time of intervention.

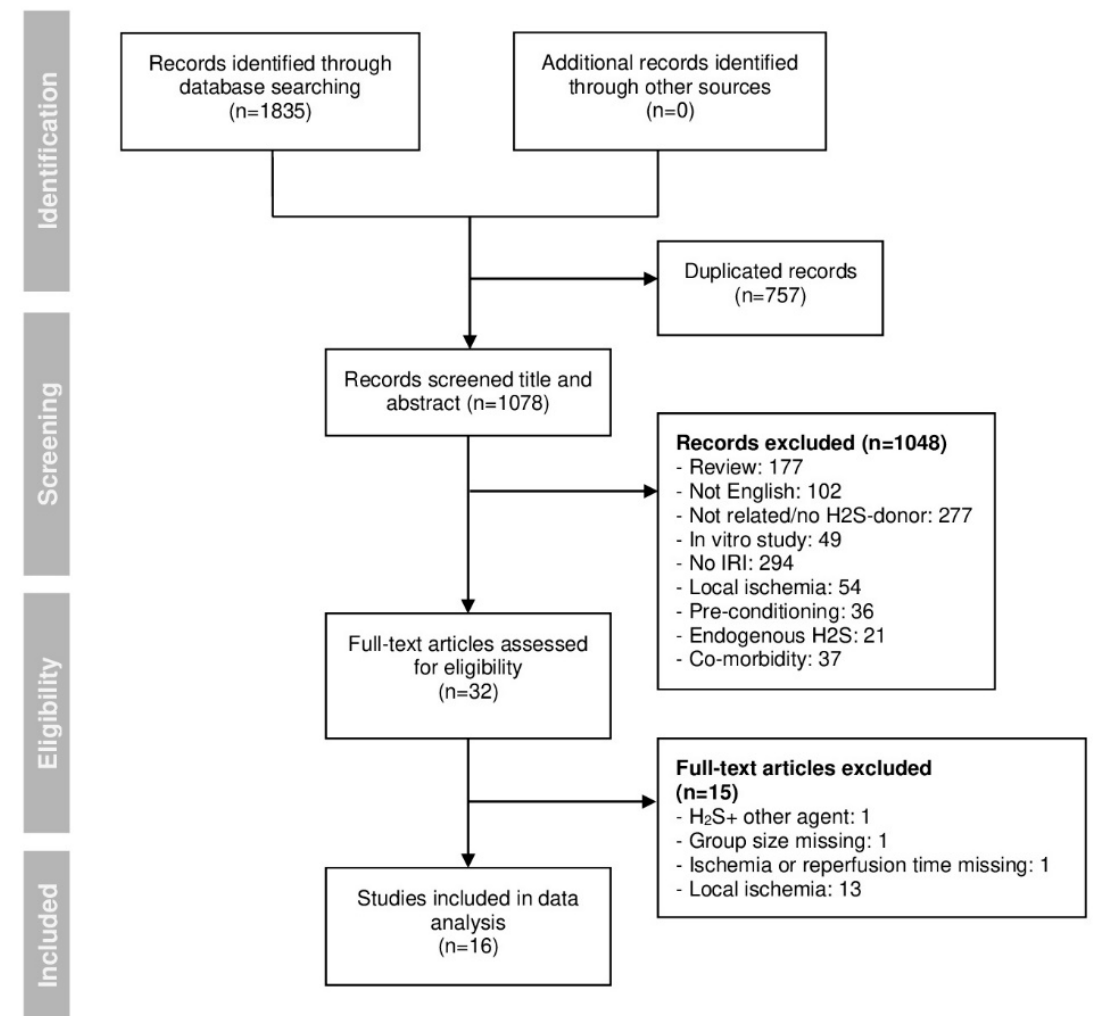

Figure 1. PRISMA flowchart of the search and selection process of the articles included in this review.

\subsection{Risk of Bias Assessment}

The use of the SYRCLE risk of bias tool to assess the quality of animal studies indicated an unknown risk of bias for most studies in the majority of categories (Figure 2). The individual risk of bias scores can be found in Table S1. The funnel plot and results from Egger's regression test showed significant publication bias $(p<0.001)$.

\subsection{Meta-Analysis}

\subsubsection{Infarct Size}

Infarct size measurements were performed in 11 studies. Postconditioning the heart using a $\mathrm{H}_{2} \mathrm{~S}$ donor resulted in a significantly smaller infarct size (standardized mean difference $(\mathrm{SMD})=-4.12,95 \%$ confidence interval $(\mathrm{CI})[-5.53--2.71], p<0.00001$; Figure 3 ). This overall effect size was accompanied by a high degree of heterogeneity (I-square $\left.\left(\mathrm{I}^{2}\right)=79 \%, p<0.00001\right)$. In sensitivity analysis, the result remained consistent after excluding the studies one by one. In addition, subgroup analysis was performed with $\mathrm{H}_{2} \mathrm{~S}$ donor groups NaHS or STS. In groups treated with STS, the infarct size was smaller when compared to groups treated with NaHS (SMD $=-9.48,95 \%$ CI [ $14.74--4.23$ ] versus $\mathrm{SMD}=-3.05,95 \% \mathrm{CI}[-4.22--1.87], p<0.02$; Figure 3$)$. 


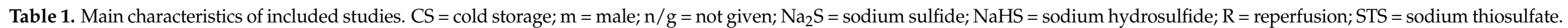

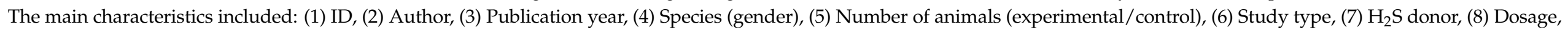

(9) Time of intervention (during CS/at time of reperfusion), (10) Route of administration, (11) Warm ischemic time (min), (12) Cold ischemic time (h) and (13) Reperfusion time (min).

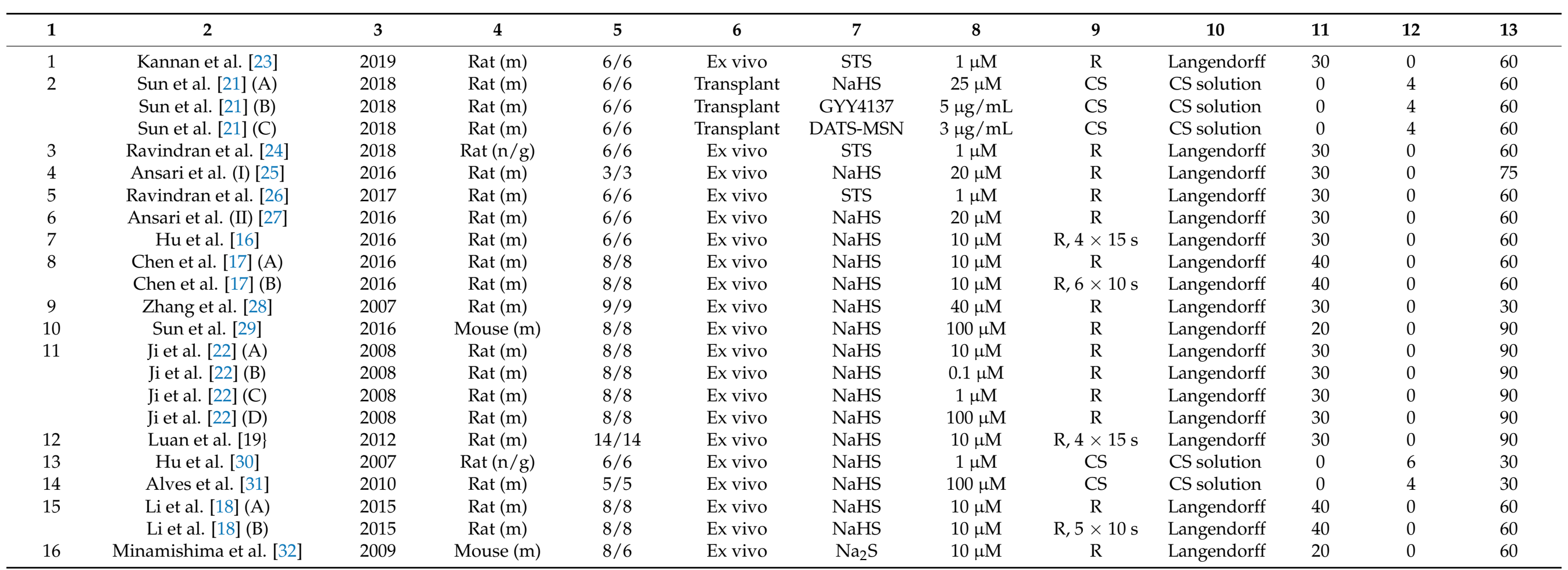




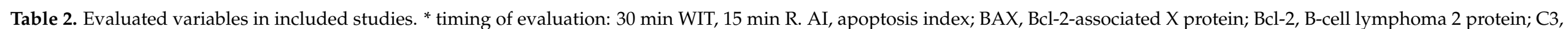

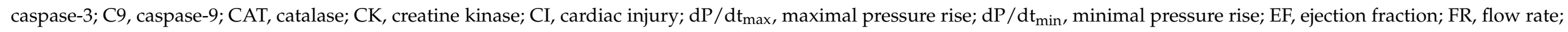

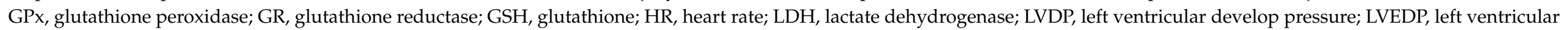

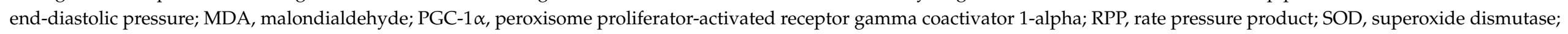
STAT3, signal transducer and activator of transcription 3.

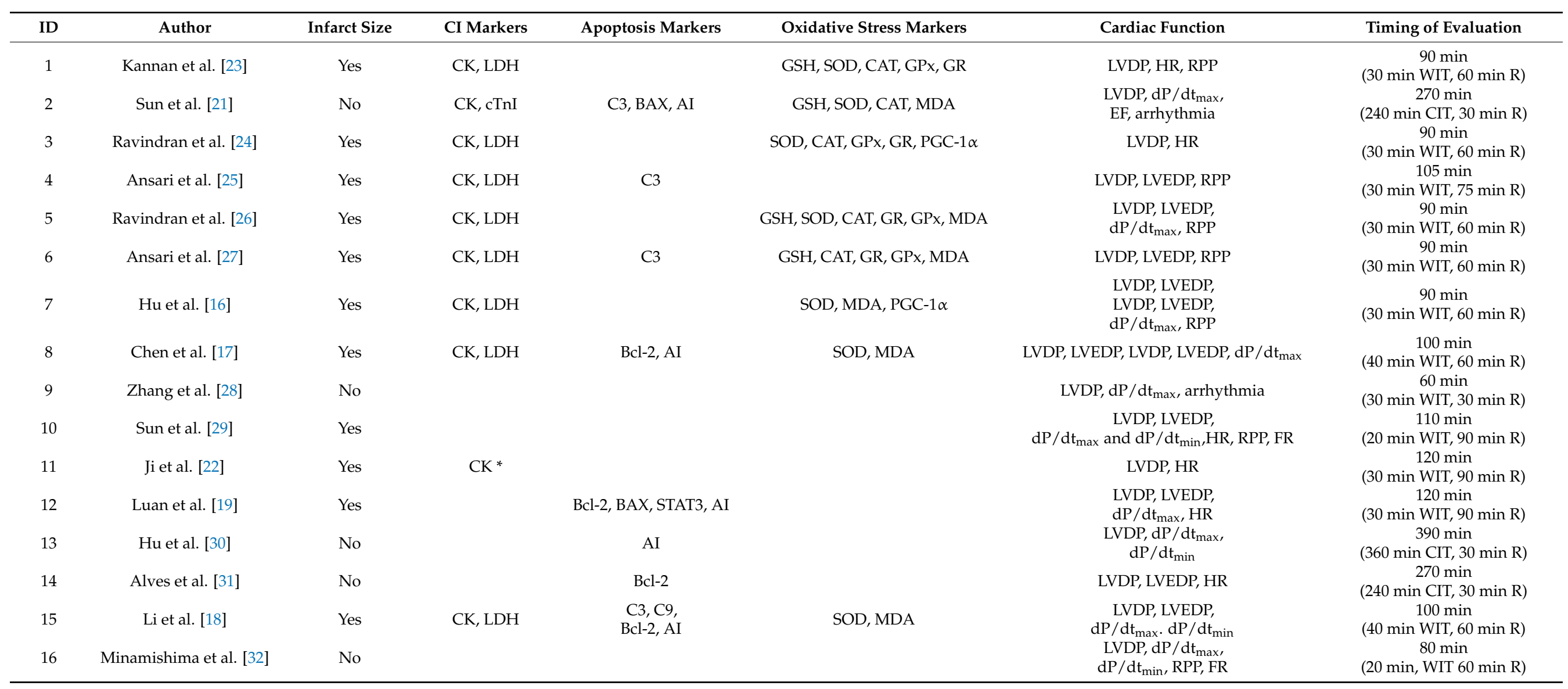




\section{(A) Reporting of quality indicators}

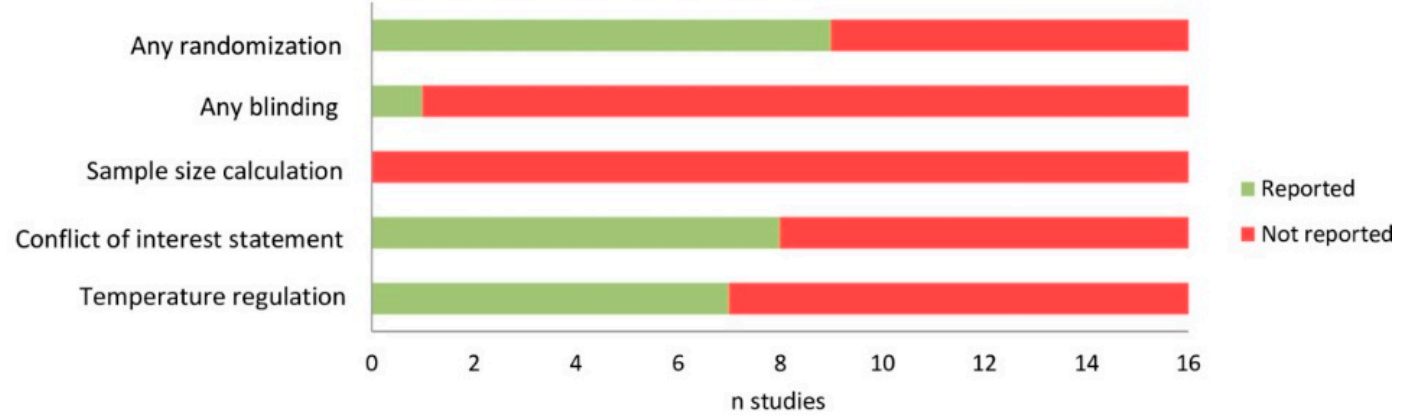

(B) Risk of bias

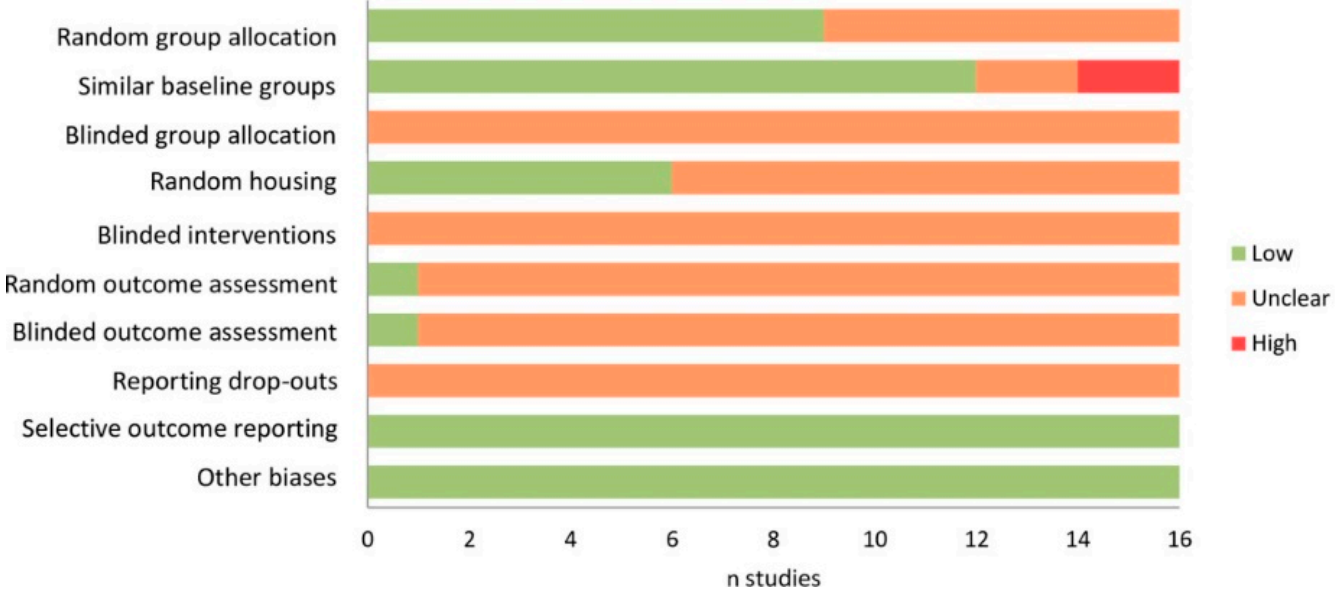

Figure 2. Quality and risk of bias assessment. Poor reporting of quality indicators (A) resulted in an unclear risk of bias for most types of bias (B). Selection bias = random group allocation, similar baseline groups and blinded group allocation. Performance bias $=$ random housing and blinded intervention. Detection bias $=$ random outcome assessment and blinded outcome assessment. Attrition bias = reporting of drop-outs. Reporting bias = selective outcome reporting.

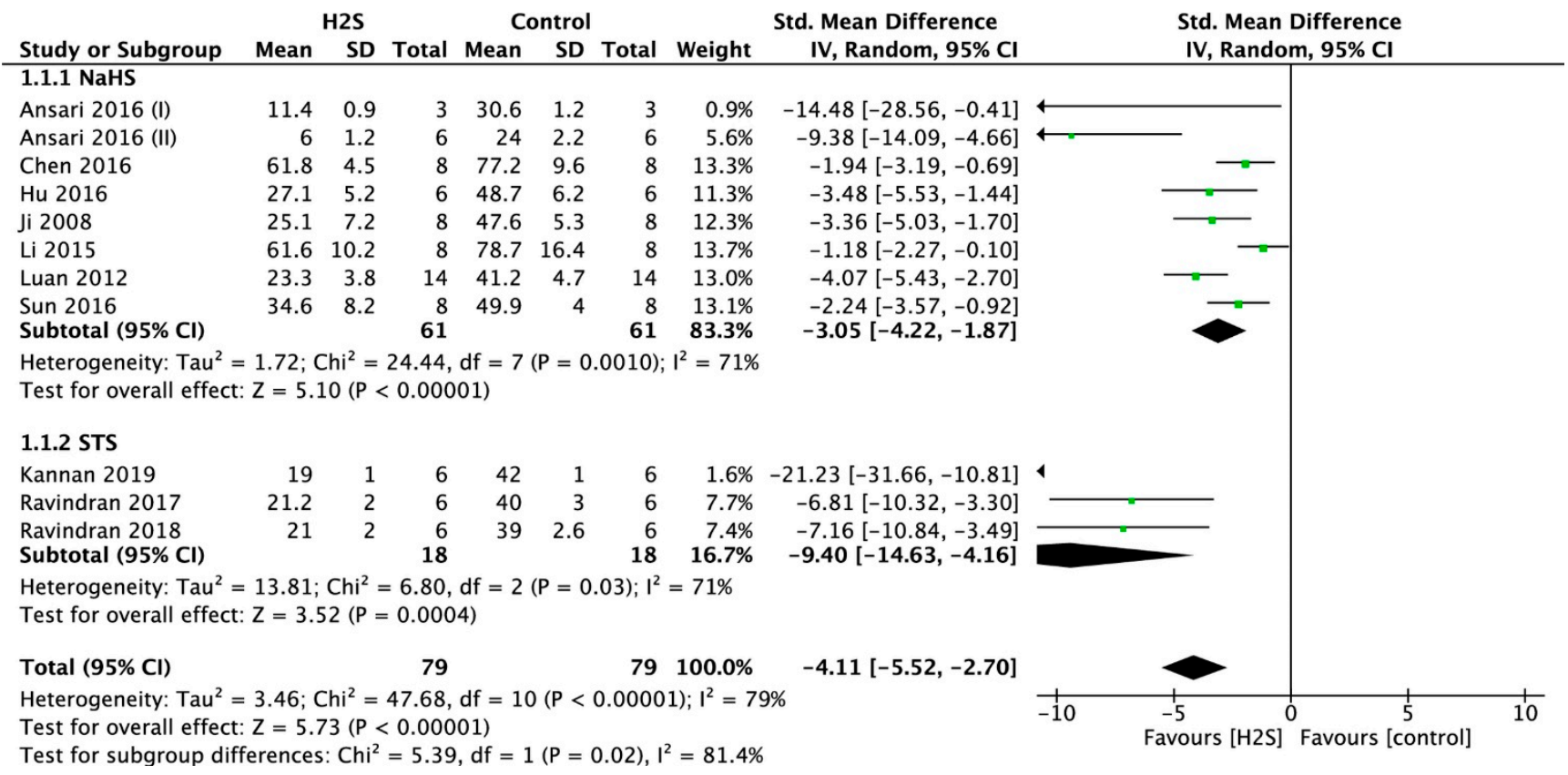

Figure 3. Forest plot of studies investigating the effect of $\mathrm{H}_{2} \mathrm{~S}$ postconditioning on myocardial infarct size. 


\subsubsection{Cardiac Injury Markers}

Meta-analysis of eight studies that reported on cardiac injury markers indicated that postconditioning with $\mathrm{H}_{2} \mathrm{~S}$ resulted in significantly lower levels of creatine kinase (CK) compared with no treatment (SMD $=-3.94,95 \% \mathrm{CI}[-5.51--2.37], p<0.00001$; Figure 4A), with statistically significant heterogeneity $\left(\mathrm{I}^{2}=79 \%, p<0.0001\right) . \mathrm{H}_{2} \mathrm{~S}$ treatment was also associated with significantly lower lactate dehydrogenase (LDH) levels measured in six studies (SMD $=-2.22,95 \% \mathrm{CI}[-3.63-0.81], p<0.002$; Figure 4B). Likewise, we observed a high degree of heterogeneity $\left(\mathrm{I}^{2}=80 \%, p<0.0002\right)$. For both outcomes, sensitivity analyses did not change the results.

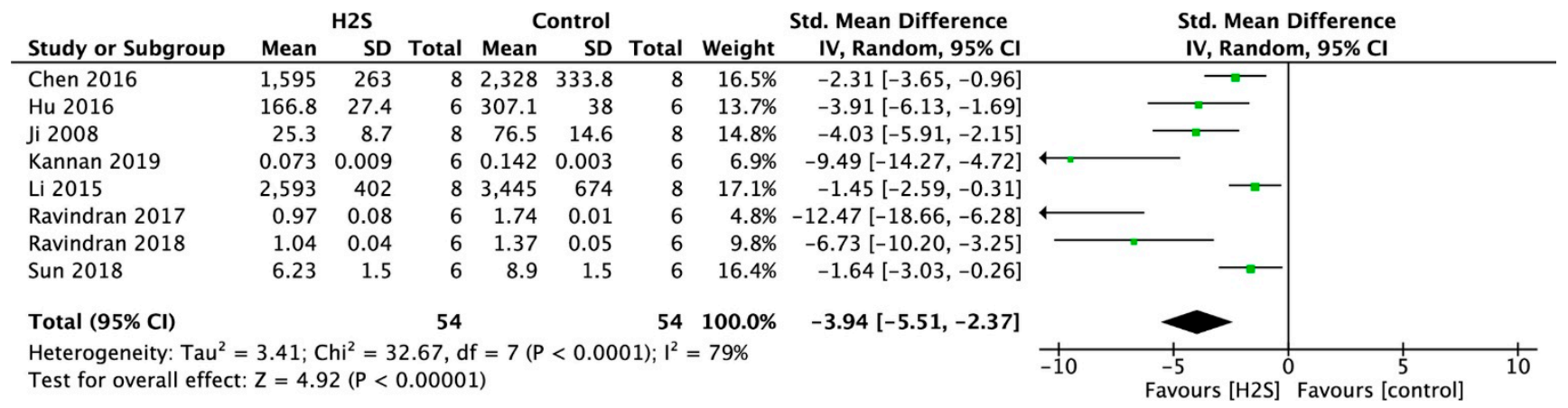

(A)

\begin{tabular}{|c|c|c|c|c|c|c|c|c|c|c|c|}
\hline \multirow[b]{2}{*}{ Study or Subgroup } & \multicolumn{3}{|c|}{$\mathrm{H} 2 \mathrm{~S}$} & \multicolumn{3}{|c|}{ Control } & \multicolumn{2}{|r|}{ Std. Mean Difference } & \multirow{2}{*}{\multicolumn{3}{|c|}{$\begin{array}{l}\text { Std. Mean Difference } \\
\text { IV, Random, } 95 \% \mathrm{CI}\end{array}$}} \\
\hline & Mean & SD & Total & Mean & SD & Total & Weight & IV, Random, 95\% Cl & & & \\
\hline Chen 2016 & 2,794 & 421.4 & 8 & 3,808 & 619.4 & 8 & $19.8 \%$ & $-1.81[-3.03,-0.59]$ & & & \\
\hline Hu 2016 & 93.6 & 17.7 & 6 & 201.5 & 14.3 & 6 & $10.5 \%$ & $-6.19[-9.42,-2.96]$ & & & \\
\hline Kannan 2019 & 1.81 & 0.2 & 6 & 3.02 & 0.15 & 6 & $10.3 \%$ & $-6.32[-9.60,-3.03]$ & & & \\
\hline Li 2015 & 1,502 & 269 & 8 & 2,292 & 450 & 8 & $19.5 \%$ & $-2.01[-3.28,-0.75]$ & & & \\
\hline Ravindran 2017 & 0.75 & 0.13 & 6 & 1.33 & 16 & 6 & $20.2 \%$ & $-0.05[-1.18,1.08]$ & & & \\
\hline Ravindran 2018 & 2.75 & 0.3 & 6 & 2.94 & 0.04 & 6 & $19.8 \%$ & $-0.82[-2.02,0.38]$ & & & \\
\hline Total $(95 \% \mathrm{Cl})$ & & & 40 & & & 40 & $100.0 \%$ & $-2.22[-3.63,-0.81]$ & & & \\
\hline $\begin{array}{l}\text { Heterogeneity: Tau } \\
\text { Test for overall effe }\end{array}$ & $\begin{array}{l}2.24 \\
Z=3\end{array}$ & $\begin{array}{l}C h i^{2}= \\
8(P=\end{array}$ & $\begin{array}{l}4.78, d f \\
0.002)\end{array}$ & $1-2$ & , & $; 1^{2}$ & $=80 \%$ & & $\begin{array}{l}-5 \\
\text { Favours [H2S] }\end{array}$ & ${ }^{+}$Favours & $\begin{array}{c}5 \\
5 \\
\text { control] }\end{array}$ \\
\hline
\end{tabular}

(B)

Figure 4. Forest plot of studies investigating the effect of $\mathrm{H}_{2} \mathrm{~S}$ postconditioning on cardiac injury markers (A) CK and (B) LDH.

\subsubsection{Oxidative Stress}

Superoxide dismutase (SOD) was measured in six studies. Meta-analysis of these studies indicated that postconditioning with $\mathrm{H}_{2} \mathrm{~S}$ was associated with significantly higher levels of SOD (SMD $=3.13,95 \%$ CI [1.61-6.65], $p=0.0009$; Figure 5A), with statistically significant heterogeneity $\left(\mathrm{I}^{2}=86 \%, p<0.00001\right)$. Meta-analysis of seven studies that reported on malondialdehyde (MDA) indicated that postconditioning with $\mathrm{H}_{2} \mathrm{~S}$ was associated with significantly lower MDA levels compared to no treatment (SMD $=-2.79,95 \% \mathrm{CI}$ [-3.97--1.60], $p<0.00001$; Figure 5B). This overall effect size was accompanied by a high degree of heterogeneity $\left(\mathrm{I}^{2}=68 \%, p<0.004\right)$. For both outcomes, sensitivity analyses did not change the results.

\subsubsection{Systolic Function}

Meta-analysis of 15 studies indicated that postconditioning with $\mathrm{H}_{2} \mathrm{~S}$ resulted in a significantly higher left ventricular (LV) developed pressure (LVDP) compared to no treatment $(\mathrm{SMD}=2.38,95 \% \mathrm{CI}[1.46-3.30], p<0.00001$; Figure $6 \mathrm{~A})$, with statistically significant heterogeneity $\left(\mathrm{I}^{2}=81 \%, p<0.00001\right)$. Postconditioning the heart using a $\mathrm{H}_{2} \mathrm{~S}$ donor resulted in a significantly higher maximum rate of $\mathrm{LV}$ pressure change $\left(\mathrm{dP} / \mathrm{dt}_{\max }\right)$ $(\mathrm{SMD}=1.41,95 \%$ CI [0.57-2.25]; Figure 6B) compared with the control $(p=0.001, n=9$ comparisons). This overall effect size was accompanied by a high degree of heterogeneity $\left(\mathrm{I}^{2}=78 \%, p<0.0001\right)$. For both outcomes, sensitivity analyses did not change the results. 


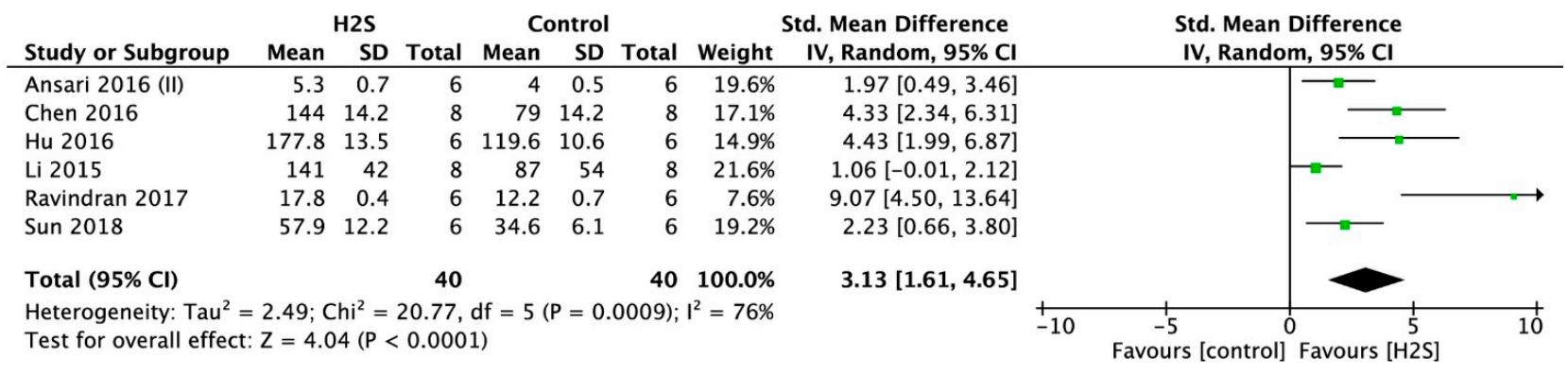

(A)

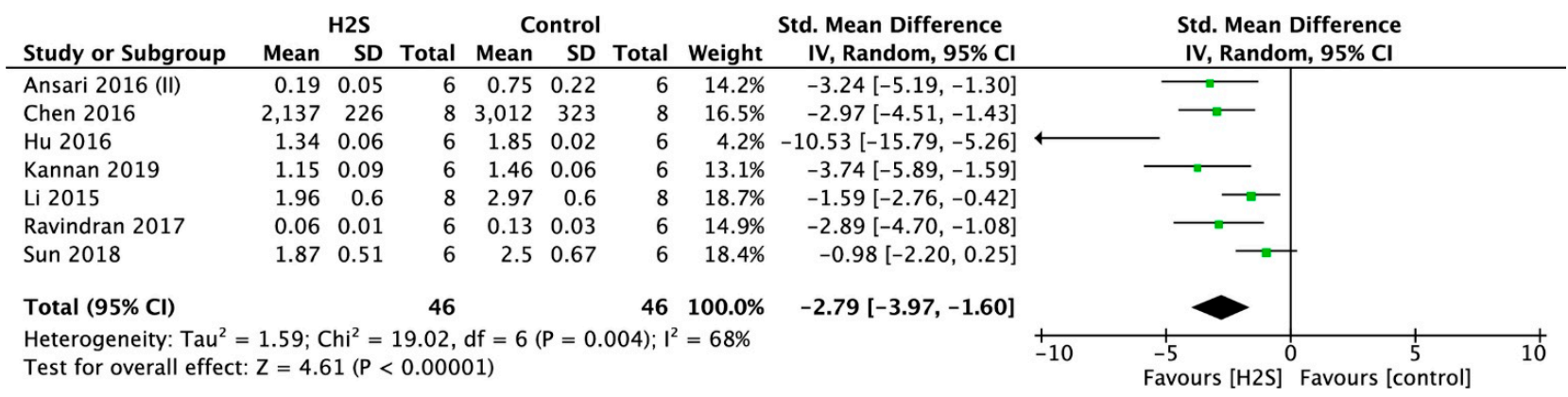

(B)

Figure 5. Forest plot of studies investigating the effect of $\mathrm{H}_{2} \mathrm{~S}$ postconditioning on oxidative stress markers (A) SOD and (B) MDA.

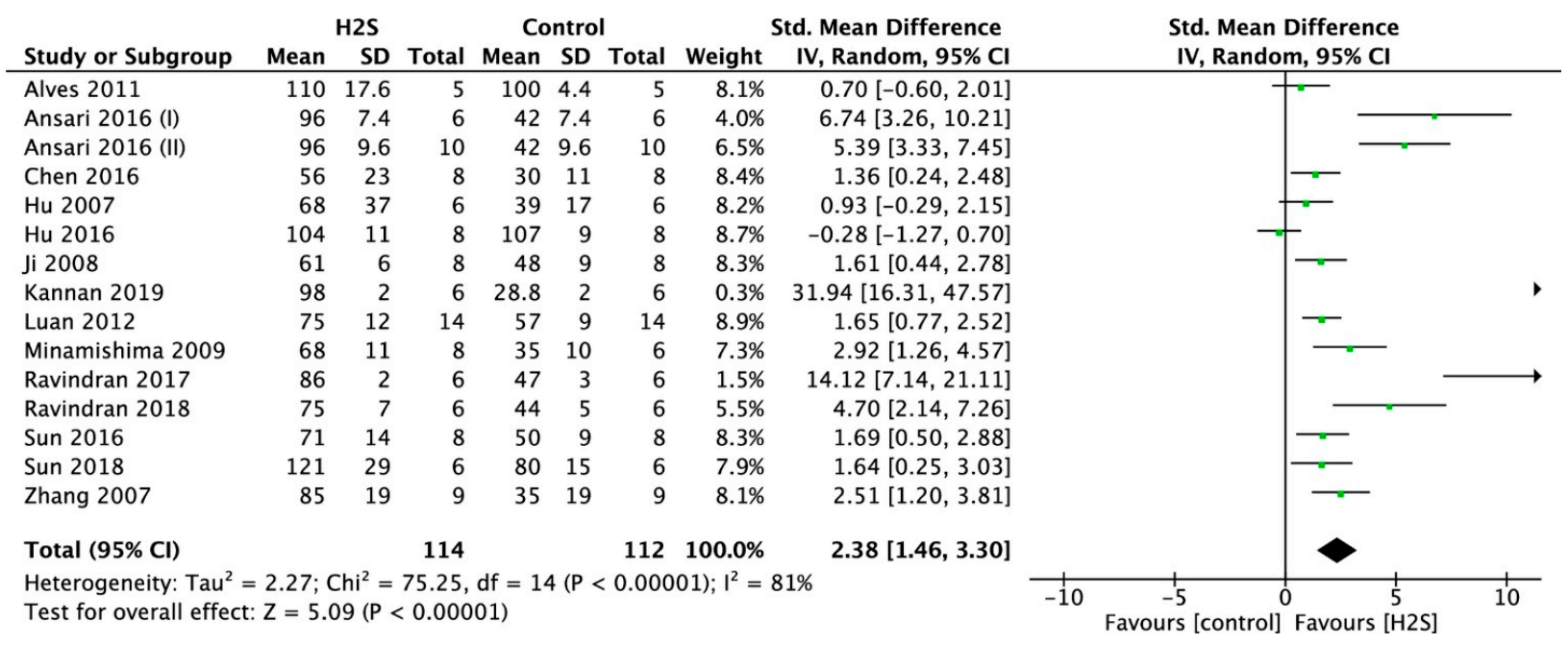

(A)

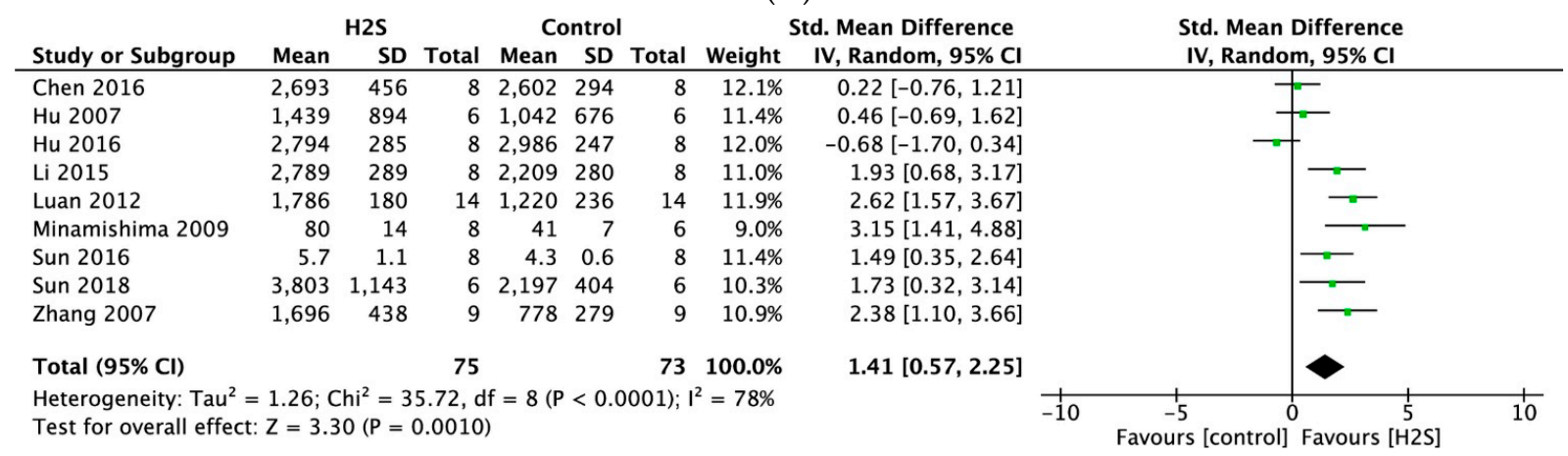

(B)

Figure 6. Forest plot of studies investigating the effect of $\mathrm{H}_{2} \mathrm{~S}$ postconditioning on systolic function parameters (A) LVDP and (B) $\mathrm{dP} / \mathrm{dt}$ max. 


\subsubsection{Diastolic Function}

Postconditioning with a $\mathrm{H}_{2} \mathrm{~S}$ donor resulted in a significantly lower $\mathrm{LV}$ end-diastolic pressure (LVEDP) (SMD = -2.59, 95\% CI [-3.99--1.18]; Figure 7A) compared with the control ( $p<0.0003, n=8$ comparisons). This overall effect size was accompanied by a high degree of heterogeneity $\left(\mathrm{I}^{2}=87 \%, p<0.00001\right)$. In the treated group, $\mathrm{H}_{2} \mathrm{~S}$ treatment also resulted in a significantly higher minimum rate of pressure change $\left(\mathrm{dP} / \mathrm{dt}_{\min }\right)(\mathrm{SMD}=1.42$, $95 \%$ CI [ $-0.76-2.09], p<0.0001, n=8$ comparisons, Figure 7B). Likewise, a high degree of heterogeneity was observed $\left(\mathrm{I}^{2}=63 \%, p=0.008\right)$. For both outcomes, sensitivity analyses did not change the results.

\subsubsection{Heart Rate}

Postconditioning with a $\mathrm{H}_{2} \mathrm{~S}$ donor resulted in a significantly higher heart rate (HR) $(\mathrm{SMD}=1.61,95 \%$ CI $[-0.03-3.24]$; Figure 8$)$ compared with the control $(p=0.05, n=6$ comparisons). This overall effect size was accompanied by a high degree of heterogeneity $\left(\mathrm{I}^{2}=86 \%, p<0.00001\right)$. Sensitivity analyses did not change the results.

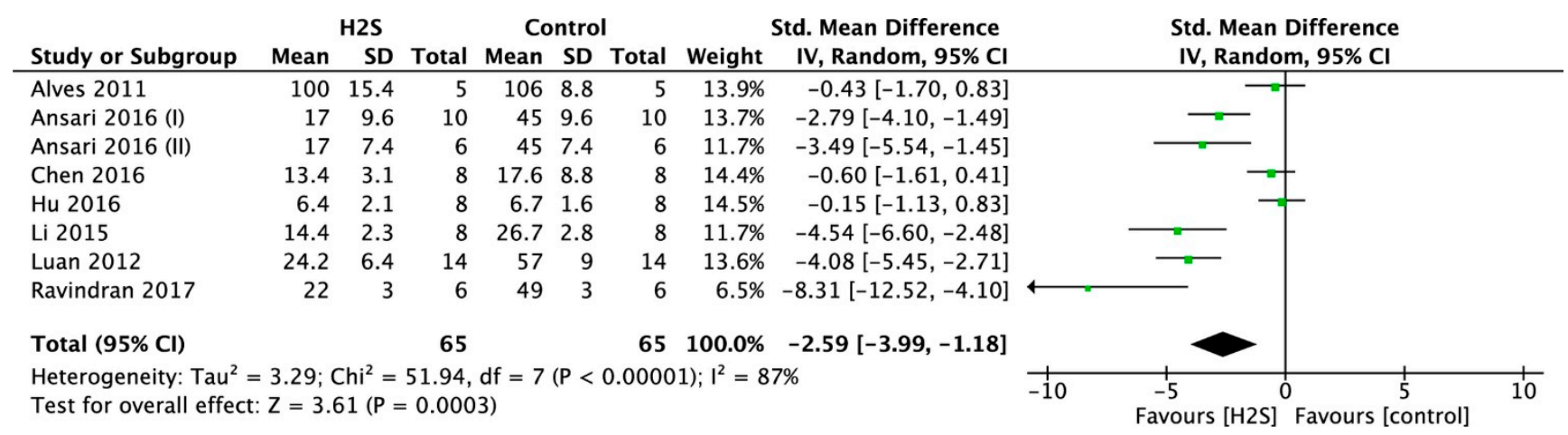

(A)

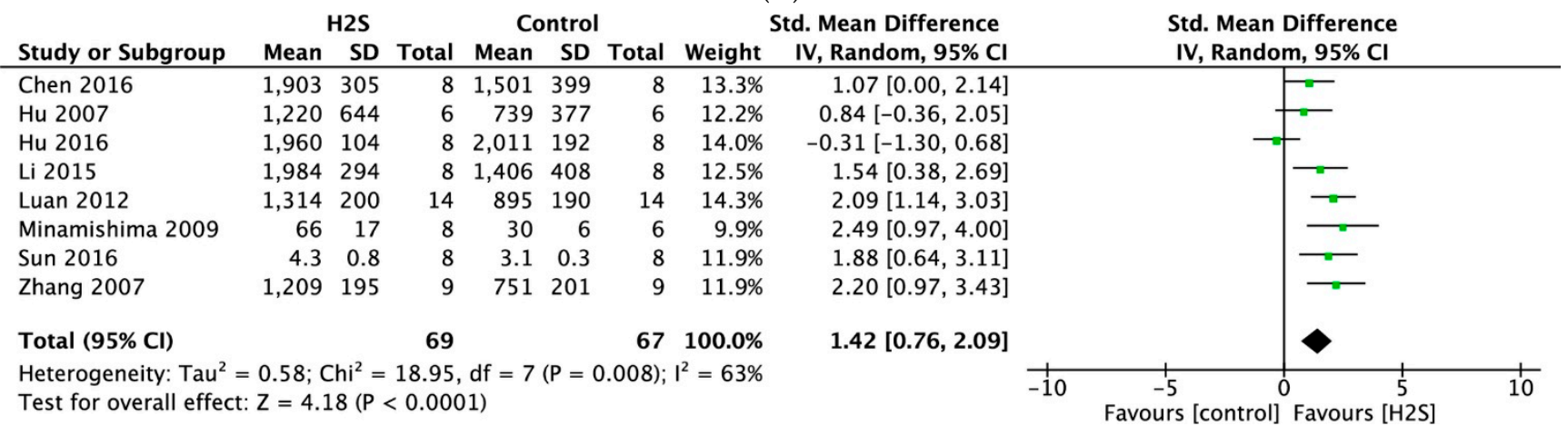

(B)

Figure 7. Forest plot of studies investigating the effect of $\mathrm{H}_{2} \mathrm{~S}$ postconditioning on diastolic function parameters (A) LVEDP and (B) $\mathrm{dP} / \mathrm{dt}$ min.

\begin{tabular}{|c|c|c|c|c|c|c|c|c|c|c|c|c|}
\hline \multirow[b]{2}{*}{ Study or Subgroup } & \multicolumn{3}{|c|}{$\mathrm{H} 2 \mathrm{~S}$} & \multicolumn{3}{|c|}{ Control } & \multicolumn{3}{|c|}{ Std. Mean Difference } & \multirow{2}{*}{\multicolumn{2}{|c|}{$\begin{array}{l}\text { Std. Mean Difference } \\
\text { IV, Random, } 95 \% \mathrm{CI}\end{array}$}} & \\
\hline & Mean & SD & Total & Mean & SD & Total & Weight & IV, Random, 95\% CI & & & & \\
\hline Alves 2011 & 124 & 26 & 5 & 78 & 20 & 5 & $19.9 \%$ & $1.79[0.19,3.39]$ & & & & \\
\hline Hu 2016 & 253 & 31 & 8 & 254 & 25 & 8 & $22.6 \%$ & $-0.03[-1.01,0.95]$ & & & & \\
\hline Kannan 2019 & 301 & 2 & 6 & 64 & 4 & 6 & $0.2 \%$ & $69.18[35.39,102.97]$ & & & & \\
\hline Luan 2012 & 241 & 18 & 14 & 207 & 28 & 14 & $23.1 \%$ & $1.40[0.56,2.24]$ & & & -- & \\
\hline Ravindran 2018 & 257 & 12 & 6 & 156 & 15 & 6 & $11.4 \%$ & $6.86[3.33,10.40]$ & & & & \\
\hline Sun 2016 & 356 & 74 & 8 & 360 & 40 & 8 & $22.6 \%$ & $-0.06[-1.04,0.92]$ & & & & \\
\hline Total $(95 \% \mathrm{CI})$ & & & 47 & & & 47 & $100.0 \%$ & $1.61[-0.03,3.24]$ & & & & \\
\hline $\begin{array}{l}\text { Heterogeneity: Tau }{ }^{2} \\
\text { Test for overall effec }\end{array}$ & $\begin{array}{l}2.82 \\
Z=1\end{array}$ & & $\begin{array}{l}=36.24 \\
=0.05\end{array}$ & , df $=$ & (1) & $<0.000$ & $001) ; I^{2}=$ & $86 \%$ & -10 & $\begin{array}{l}-5 \\
\text { urs [ }\end{array}$ & Favours $\left[\begin{array}{r}5 \\
\end{array}\right.$ & 10 \\
\hline
\end{tabular}

Figure 8. Forest plot of studies investigating the effect of $\mathrm{H}_{2} \mathrm{~S}$ postconditioning on $\mathrm{HR}$. 


\subsection{Meta-Regression Analysis}

Meta-regression analyses found a significant association between the used $\mathrm{H}_{2} \mathrm{~S}$ donor and CK $(p=0.008)$, and a trend towards a significant association between $\mathrm{H}_{2} \mathrm{~S}$ donor and infarct size $(p=0.05)$ and SOD $(p=0.053)$. In these outcome variables, STS was more favorable than NaHS. Meta-regression analysis also found a significant association between route of administration and MDA $(p=0.04)$, with Langendorff being more favorable than CS. No significant association was identified for all other outcomes (LDH, SOD, LVDP, $\mathrm{dP} / \mathrm{dtmin}, \mathrm{dP} / \mathrm{dtmax}, \mathrm{LVEDP}$ and HR). Meta-regression of the postconditioning method (single bolus versus ischemic conditioning) showed no significant association with one of the outcomes as well.

\section{Discussion}

In the present systematic review and meta-analysis, we examined the existing experimental data on $\mathrm{H}_{2} \mathrm{~S}$ postconditioning against global myocardial IRI in animal studies. We aimed at including all existing studies that used $\mathrm{H}_{2} \mathrm{~S}$ treatment against IRI induced by low or absent coronary flow in the whole heart (global ischemia). Furthermore, we aimed to determine whether findings in this field are consistent, since clinical translation of $\mathrm{H}_{2} \mathrm{~S}$ treatment for optimization of donor heart preservation could be of additional value. In all the 16 studies reviewed and in meta-analyses, we observed that $\mathrm{H}_{2} \mathrm{~S}$ donors protect the heart against IRI. $\mathrm{H}_{2} \mathrm{~S}$ postconditioning resulted in a significantly smaller infarct size, with greater effect in studies using STS as a $\mathrm{H}_{2} \mathrm{~S}$ donor compared with studies using NaHS as a $\mathrm{H}_{2} \mathrm{~S}$ donor. Furthermore, $\mathrm{H}_{2} \mathrm{~S}$ postconditioning consistently resulted in significantly lower release of cardiac injury markers, lower markers of oxidative stress and higher cardiac function. Postconditioning with STS also showed significant advantageous effects in decreasing CK levels compared with NaHS. Nevertheless, the notable heterogeneity across studies must be highlighted. The infarct-limiting effects of $\mathrm{H}_{2} \mathrm{~S}$ were also evaluated in local ischemia in vivo studies. Karwi et al. evaluated the effects of $\mathrm{H}_{2} \mathrm{~S}$ pre- and postconditioning on myocardial infarction across in vivo preclinical studies using a comprehensive systematic review followed by meta-analysis [33]. This study showed significant infarctsparing effects of $\mathrm{H}_{2} \mathrm{~S}$, which is in line with our results, emphasizing the infarct-limiting effects of $\mathrm{H}_{2} \mathrm{~S}$ and potential clinical application in local and global myocardial protection against ischemia.

The most commonly used $\mathrm{H}_{2} \mathrm{~S}$ donor in the reviewed papers is NaHS $(n=13)$, a fast $\mathrm{H}_{2} \mathrm{~S}$-releasing inorganic sulfide salt [34]. It was shown that NaHS can preserve cardiac function and reduce myocardial tissue damage in postconditioning studies. However, it is important to note that the cardioprotective effects of $\mathrm{H}_{2} \mathrm{~S}$ depend on its physiological concentration. Subnormal tissue concentrations or low release rates of $\mathrm{H}_{2} \mathrm{~S}$ have the most beneficial effect without toxicity [34]. However, at high concentrations or high release rates, $\mathrm{H}_{2} \mathrm{~S}$ can induce toxicity and cell damage [35]. NaHS releases $\mathrm{H}_{2} \mathrm{~S}$ instantaneously in aqueous solution, resulting in a high concentration of $\mathrm{H}_{2} \mathrm{~S}$ within seconds and a short effective residence time in cardiac tissue [36]. To prevent the potential $\mathrm{H}_{2} \mathrm{~S}$ toxicity, controllable and slow-releasing $\mathrm{H}_{2} \mathrm{~S}$ donors have been designed and successfully demonstrated to have cardioprotective effects [21,36]. One of these controllable $\mathrm{H}_{2} \mathrm{~S}$ sources is STS, a metabolite of the $\mathrm{H}_{2} \mathrm{~S}$ detoxification process which can be adversely used to regenerate $\mathrm{H}_{2} \mathrm{~S}$. Apart from being a source of $\mathrm{H}_{2} \mathrm{~S}$, STS itself acts as a calcium chelator and antioxidant [23]. As mentioned before, STS treatment showed in this study more advantageous effects related to infarct size and levels of CK compared to NaHS treatment. STS has great potential due to both the $\mathrm{H}_{2} \mathrm{~S}$-related effects and the complementary effects of STS itself. Furthermore, additional anti-inflammatory and antioxidant effects of STS are related to its reaction with mitochondrial thiosulfate sulfurtransferase and its subsequent ROS scavenging effects [37]. In addition, $\mathrm{pH}$-sensitive $\mathrm{H}_{2} \mathrm{~S}$ donors have been developed including intramolecular cyclization-based donors (JK) and ammonium tetrathiomolybdate (ATTM) [38,39]. Since ischemic injury leads to reduced $\mathrm{pH}$ levels and acidosis, acid-promoted $\mathrm{H}_{2} \mathrm{~S}$ release could be of significance in treating IRI. Both JK donors and ATTM have shown efficiency in 
reducing cellular damage and limiting infarct size in local ischemia models. In conclusion, slow-releasing and controllable $\mathrm{H}_{2} \mathrm{~S}$ donors have more clinical potential than fast-releasing $\mathrm{H}_{2} \mathrm{~S}$ donors.

In addition to paying attention to the $\mathrm{H}_{2} \mathrm{~S}$ donor choice, the route of administration should be chosen carefully. In this study, subgroup analyses showed that $\mathrm{H}_{2} \mathrm{~S}$ administered in Langendorff perfusate was more advantageous than $\mathrm{H}_{2} \mathrm{~S}$ supplementation in $\mathrm{CS}$ solution with regard to lowered MDA levels. Further studies are needed to evaluate the effectiveness of $\mathrm{H}_{2} \mathrm{~S}$ postconditioning in static $\mathrm{CS}$ versus $\mathrm{H}_{2} \mathrm{~S}$ usage during reperfusion of the heart, for example, during Buckberg reperfusion [40].

The present study has some limitations. The literature search was restricted to the English language. We acknowledge that this restriction may have led to incomplete retrieval of relevant data. In addition, articles by the same research groups were included, assuming good adherence to scientific integrity, as in this way, valuable results were not overlooked. Lastly, we collected data on various markers of IRI without including time points for assessment of these markers. This might make the interpretation of the results difficult since more damage may occur over time, or, on the contrary, a longer treatment time may improve outcomes.

An important limitation we observed in the included studies is that none of the studies were performed in large animals. Although no single animal model perfectly recreates human pathophysiology, large animal models of cardiovascular research are more eligible for clinical translation than small animal models since determinants of myocardial work, e.g., HR, myocardial energy consumption and anatomy, are more similar between humans and large animals. Furthermore, the differences in the pharmacokinetics, distribution and metabolism of $\mathrm{H}_{2} \mathrm{~S}$ between small and large animals may complicate the step to clinical translation [41]. Therefore, more large animal models for testing the efficacy and safety of $\mathrm{H}_{2} \mathrm{~S}$ treatment against IRI are required before translating $\mathrm{H}_{2} \mathrm{~S}$ therapy for organ preservation to the clinic. Another important aspect we observed in the animal studies is that none of the studies included female animals. Female hearts have an inherent cardioprotective advantage due to a lower inflammatory response in the ischemic myocardium compared to men [42]. Female rat hearts show significantly smaller infarct sizes than male hearts, indicating that there is a sex-specific difference in susceptibility to tissue damage induced by IRI [43]. Female animals or mixed gender studies need to be conducted to explore the sex differences in the susceptibility to IRI and efficiency of $\mathrm{H}_{2} \mathrm{~S}$ treatment against IRI. Furthermore, when looking at study models, all included studies performed beating heart procurements, and none of the studies applied $\mathrm{H}_{2} \mathrm{~S}$ postconditioning in a DCD procedure. Therefore, further studies need to be conducted to explore the possibilities to preserve DCD heart function with $\mathrm{H}_{2} \mathrm{~S}$, in order to enlarge the donor pool for transplantation with DCD hearts.

Long-term effects of $\mathrm{H}_{2} \mathrm{~S}$ treatment were described in only one of the sixteen papers we reviewed (8-week follow-up time) [21]. Mostly, cardioprotective effects by $\mathrm{H}_{2} \mathrm{~S}$ were investigated after a single dose shortly before ischemia or after reperfusion. As stated previously, transplantation of the treated heart would require long-term evaluation of the cardioprotective effects on the heart. Further (transplantation) studies are needed to determine time-dependent effects of $\mathrm{H}_{2} \mathrm{~S}$ treatment against IRI and evaluate possible beneficial and detrimental effects on all organs, especially in larger animal models since long-term effects of $\mathrm{H}_{2} \mathrm{~S}$ postconditioning against IRI in large animals are not known yet.

\section{Materials and Methods}

This study was conducted according to the Preferred Reporting Items for Systematic Reviews and Meta-Analysis (PRISMA) guidelines [44].

\subsection{Search Strategy}

A systematic electronic literature search was performed using Medline, Cinahl and Embase databases, from inception to 25 August 2020. We used combinations of search 
terms and keywords including "heart", "organ transplantation", "organ preservation", "hydrogen sulfide" and "reperfusion injury". Full search terms can be found in Table S2. We performed hand searching of the reference list of selected articles from the electronic searches to ensure inclusion of any studies not found by the primary search.

\subsection{Eligibility Criteria}

Eligibility criteria were developed in accordance with the PICOS approach [45]. Studies were included if they met the following eligibility criteria: (1) original article examining the effects of postconditioning the heart with $\mathrm{H}_{2} \mathrm{~S}$ to limit IRI; (2) in situ or ex situ study; (3) myocardial ischemia was induced by complete cessation of coronary flow (global ischemia model); (4) one or more of the following outcome variables were included in the study: myocardial infarct size, cardiac injury markers, inflammation, oxidative stress or cardiac function. Studies without a documented ischemia and reperfusion time, type of exogenous $\mathrm{H}_{2} \mathrm{~S}$ donor, $\mathrm{H}_{2} \mathrm{~S}$ donor dosage, timing and route of administration were excluded. Studies were also excluded if the $\mathrm{H}_{2} \mathrm{~S}$ donor was administered in combination with another pharmacological treatment, and studies involving animal models with induced non-coronary/non-myocardial diseases at baseline were also excluded.

\subsection{Data Extraction}

Data extraction was performed by one reviewer. If inclusion of articles was questionable, a second and a third reviewer reviewed these particular articles. Publications were retrieved from the electronic literature databases and checked for duplication. Initially, the references were reviewed based on the titles and abstracts. Then, relevant articles were fully read and assessed. Study characteristics were divided into first author, publication year, species, gender, number of included animals, study type (in or ex situ), $\mathrm{H}_{2} \mathrm{~S}$ donor, dosage, time of intervention and route of administration of the $\mathrm{H}_{2} \mathrm{~S}$ donor. The primary outcome variable was myocardial infarct size. Secondary outcome variables were divided into cardiac injury markers, inflammation, oxidative stress and functional parameters.

\subsection{Risk of Bias Assessment}

Risk of bias was assessed using SYRCLE's RoB tool [46]. This tool, based on the Cochrane Collaboration RoB Tool, aims to assess methodological quality and has been adapted to aspects of bias that play a role in animal experiments, including (1) selection bias, (2) performance bias, (3) detection bias, (4) attrition bias and (5) reporting bias.

\subsection{Statistical Analysis}

All outcome measures were treated as continuous data. Data were presented as SMD with $95 \%$ CI. Every outcome evaluated in at least five studies was analyzed. The random effects model was used for pooling results. The $\mathrm{H}_{2} \mathrm{~S}$-treated group was compared with the control group (no treatment/placebo) by use of the weighted mean difference (WMD). Heterogeneity was quantified using the $\mathrm{I}^{2}$ statistics test. An $\mathrm{I}^{2}$ higher than $50 \%$ was considered indicative of significant heterogeneity. Forest plots were created to summarize the meta-analysis study results. Meta-regression analyses were performed to examine an association between type of $\mathrm{H}_{2} \mathrm{~S}$ donor, postconditioning method (single bolus or ischemic conditioning) and route of administration in all outcome variables. Publication bias was assessed by inspection of funnel plots and quantified by Egger's test. A $p$-value $<0.05$ was considered statistically significant. Statistical analyses and figures were performed and composed with Review Manager (RevMan 5.3.5 Copenhagen, Denmark: The Nordic Cochrane Centre, The Cochrane Collaboration, 2014) and Stata (StataCorp, College, TX, USA).

\section{Conclusions}

This systematic review provides an overview of the cardioprotective effects of $\mathrm{H}_{2} \mathrm{~S}$ postconditioning against IRI in the setting of global ischemia. The included studies showed robust beneficial effects of $\mathrm{H}_{2} \mathrm{~S}$ postconditioning with regard to infarct size, cardiac injury 
markers, oxidative stress and cardiac function. Postconditioning with slow-releasing $\mathrm{H}_{2} \mathrm{~S}$ donors might offer a valuable opportunity for novel therapies within cardiac preservation for transplantation. Before clinical implication, studies evaluating the (long-term) effects of $\mathrm{H}_{2} \mathrm{~S}$ treatment in large and female/mixed animal studies are warranted.

Supplementary Materials: The following are available online at https:/ /www.mdpi.com/article/10 $.3390 /$ ijms22115737/s1.

Author Contributions: I.A.E., investigation, formal analysis and writing; V.v.S., investigation and writing; K.D., formal analysis; M.-S.L.Y.d.K., writing; H.v.G., conceptualization, supervision and writing; M.E.E., conceptualization, supervision and writing. All authors have read and agreed to the published version of the manuscript.

Funding: This research received no external funding.

Institutional Review Board Statement: Not applicable.

Informed Consent Statement: Not applicable.

Data Availability Statement: No new data were created or analyzed in this study. Data sharing is not applicable to this article.

Conflicts of Interest: The authors declare no conflict of interest.

\section{References}

1. Virani, S.S.; Alonso, A.; Benjamin, E.J.; Bittencourt, M.S.; Callaway, C.W.; Carson, A.P.; Chamberlain, A.M.; Chang, A.R.; Cheng, S.; Delling, F.N.; et al. Heart Disease and Stroke Statistics-2020 Update: A Report from the American Heart Association. Circulation 2020, 141, e139-e596. [CrossRef] [PubMed]

2. Yellon, D.M.; Hausenloy, D.J. Myocardial Reperfusion Injury. New Engl. J. Med. 2007, 357, 1121-1135. [CrossRef]

3. Matsumura, K.; Jeremy, R.W.; Schaper, J.; Becker, L.C. Progression of Myocardial Necrosis during Reperfusion of Ischemic Myocardium. Circulation 1998, 97, 795-804. [CrossRef] [PubMed]

4. Eltzschig, H.K.; Eckle, T. Ischemia and reperfusion—from mechanism to translation. Nat. Med. 2011, 17, 1391-1401. [CrossRef] [PubMed]

5. Vinten-Johansen, J.; Jiang, R.; Reeves, J.G.; Mykytenko, J.; Deneve, J.; Jobe, L.J. Inflammation, Proinflammatory Mediators and Myocardial Ischemia-reperfusion Injury. Hematol. Clin. N. Am. 2007, 21, 123-145. [CrossRef]

6. Hausenloy, D.J.; Yellon, D.M. Myocardial ischemia-reperfusion injury: A neglected therapeutic target. J. Clin. Investig. 2013, 123, 92-100. [CrossRef] [PubMed]

7. Banner, N.R.; Thomas, H.L.; Curnow, E.; Hussey, J.C.; Rogers, C.A.; Bonser, R.S. The Importance of Cold and Warm Cardiac Ischemia for Survival after Heart Transplantation. Transplantation 2008, 86, 542-547. [CrossRef] [PubMed]

8. Quader, M.; Toldo, S.; Chen, Q.; Hundley, G.; Kasirajan, V. Heart transplantation from donation after circulatory death donors: Present and future. J. Card. Surg. 2020, 35, 875-885. [CrossRef] [PubMed]

9. Kimura, H. Production and Physiological Effects of Hydrogen Sulfide. Antioxid. Redox Signal. 2014, 20, 783-793. [CrossRef] [PubMed]

10. Zhao, W.; Zhang, J.; Lu, Y.; Wang, R. The vasorelaxant effect of $\mathrm{H}_{2} \mathrm{~S}$ as a novel endogenous gaseous KATP channel opener. EMBO J. 2001, 20, 6008-6016. [CrossRef]

11. Wu, D.; Wang, J.; Li, H.; Xue, M.; Ji, A.; Li, Y. Role of Hydrogen Sulfide in Ischemia-Reperfusion Injury. Oxidative Med. Cell. Longev. 2015, 2015, 1-16. [CrossRef]

12. Zanardo, R.C.O.; Brancaleone, V.; Distrutti, E.; Fiorucci, S.; Cirino, G.; Wallace, J.L. Hydrogen sulfide is an endogenous modulator of leukocyte-mediated inflammation. FASEB J. 2006, 20, 2118-2120. [CrossRef]

13. Elrod, J.; Calvert, J.; Morrison, J.; Doeller, J.E.; Kraus, D.W.; Tao, L.; Jiao, X.; Scalia, R.; Kiss, L.; Szabo, C.; et al. Hydrogen sulfide attenuates myocardial ischemia-reperfusion injury by preservation of mitochondrial function. Proc. Natl. Acad. Sci. USA 2007, 104, 15560-15565. [CrossRef]

14. Wu, D.; Hu, Q.; Liu, X.; Pan, L.; Xiong, Q.; Zhu, Y.Z. Hydrogen sulfide protects against apoptosis under oxidative stress through SIRT1 pathway in H9c2 cardiomyocytes. Nitric Oxide 2015, 46, 204-212. [CrossRef]

15. Fu, M.; Zhang, W.; Wu, L.; Yang, G.; Li, H.; Wang, R. Hydrogen sulfide $\left(\mathrm{H}_{2} \mathrm{~S}\right)$ metabolism in mitochondria and its regulatory role in energy production. Proc. Natl. Acad. Sci. USA 2012, 109, 2943-2948. [CrossRef]

16. Hu, M.-Z.; Zhou, B.; Mao, H.-Y.; Sheng, Q.; Du, B.; Chen, J.-L.; Pang, Q.-F.; Ji, Y. Exogenous Hydrogen Sulfide Postconditioning Protects Isolated Rat Hearts From Ischemia/Reperfusion Injury Through Sirt1/PGC-1 $\alpha$ Signaling Pathway. Int. Heart J. 2016, 57, 477-482. [CrossRef] 
17. Chen, J.; Gao, J.; Sun, W.; Li, L.; Wang, Y.; Bai, S.; Li, X.; Wang, R.; Wu, L.; Li, H.; et al. Involvement of exogenous $\mathrm{H}_{2} \mathrm{~S}$ in recovery of cardioprotection from ischemic post-conditioning via increase of autophagy in the aged hearts. Int. J. Cardiol. 2016, 220, 681-692. [CrossRef]

18. Li, H.; Wang, Y.; Wei, C.; Bai, S.; Zhao, Y.; Li, H.; Wu, B.; Wang, R.; Wu, L.; Xu, C. Mediation of exogenous hydrogen sulfide in recovery of ischemic post-conditioning-induced cardioprotection via down-regulating oxidative stress and up-regulating PI3K/Akt/GSK-3 $\beta$ pathway in isolated aging rat hearts. Cell Biosci. 2015, 5, 11. [CrossRef]

19. Luan, H.-F.; Zhao, Z.-B.; Zhao, Q.-H.; Zhu, P.; Xiu, M.-Y.; Ji, Y. Hydrogen sulfide postconditioning protects isolated rat hearts against ischemia and reperfusion injury mediated by the JAK2/STAT3 survival pathway. Braz. J. Med. Biol. Res. 2012, 45, 898-905. [CrossRef]

20. Redfors, B.; Shao, Y.; Omerovic, E. Myocardial infarct size and area at risk assessment in mice. Exp. Clin. Cardiol. 2012, 17, 268-272.

21. Sun, X.; Wang, W.; Dai, J.; Huang, J.; Shi, M.; Chu, X.; Wang, F.; Guo, C.; Wang, C.; Pang, L.; et al. Donor heart preservation with a novel long-term and slow-releasing hydrogen sulfide system. Nitric Oxide 2018, 81, 1-10. [CrossRef]

22. Ji, Y.; Pang, Q.-F.; Xu, G.; Wang, L.; Wang, J.-K.; Zeng, Y.-M. Exogenous hydrogen sulfide postconditioning protects isolated rat hearts against ischemia-reperfusion injury. Eur. J. Pharmacol. 2008, 587, 1-7. [CrossRef]

23. Kannan, S.; Boovarahan, S.R.; Rengaraju, J.; Prem, P.; Kurian, G.A. Attenuation of cardiac ischemia-reperfusion injury by sodium thiosulfate is partially dependent on the effect of cystathione beta synthase in the myocardium. Cell Biophys. 2019, 77, 261-272. [CrossRef] [PubMed]

24. Ravindran, S.; Kurian, G.A. Effect of Sodium Thiosulfate Postconditioning on Ischemia-Reperfusion Injury Induced Mitochondrial Dysfunction in Rat Heart. J. Cardiovasc. Transl. Res. 2018, 11, 246-258. [CrossRef]

25. Ansari, S.B.; Kurian, G.A. Hydrogen sulfide modulates sub-cellular susceptibility to oxidative stress induced by myocardial ischemic reperfusion injury. Chem. Interact. 2016, 252, 28-35. [CrossRef]

26. Ravindran, S.; Hussain, S.J.; Boovarahan, S.R.; Kurian, G.A. Sodium thiosulfate post-conditioning protects rat hearts against ischemia reperfusion injury via reduction of apoptosis and oxidative stress. Chem. Interact. 2017, 274, 24-34. [CrossRef]

27. Banu, S.A.; Ravindran, S.; Kurian, G.A. Hydrogen sulfide post-conditioning preserves interfibrillar mitochondria of rat heart during ischemia reperfusion injury. Cell Stress Chaperones 2016, 21, 571-582. [CrossRef]

28. Zhang, Z.; Huang, H.; Liu, P.; Tang, C.; Wang, J. Hydrogen sulfide contributes to cardioprotection during ischemia-reperfusion injury by opening KATP channels. Can. J. Physiol. Pharmacol. 2007, 85, 1248-1253. [CrossRef]

29. Sun, J.; Aponte, A.M.; Menazza, S.; Gucek, M.; Steenbergen, C.; Murphy, E. Additive cardioprotection by pharmacological postconditioning with hydrogen sulfide and nitric oxide donors in mouse heart: S-sulfhydration vs. S-nitrosylation. Cardiovasc. Res. 2016, 110, 96-106. [CrossRef]

30. Hu, X.; Li, T.; Bi, S.; Jin, Z.; Zhou, G.; Bai, C.; Li, L.; Cui, Q.; Liu, W. Possible Role of Hydrogen Sulfide on the Preservation of Donor Rat Hearts. Transplant. Proc. 2007, 39, 3024-3029. [CrossRef]

31. Alves, M.G.; Soares, A.F.; Carvalho, R.A.; Oliveira, P.J. Sodium hydrosulfide improves the protective potential of the cardioplegic histidine buffer solution. Eur. J. Pharmacol. 2011, 654, 60-67. [CrossRef]

32. Minamishima, S.; Bougaki, M.; Sips, P.Y.; De Yu, J.; Minamishima, Y.A.; Elrod, J.; Lefer, D.J.; Bloch, K.D.; Ichinose, F. Hydrogen Sulfide Improves Survival After Cardiac Arrest and Cardiopulmonary Resuscitation via a Nitric Oxide Synthase 3-Dependent Mechanism in Mice. Circulation 2009, 120, 888-896. [CrossRef]

33. Karwi, Q.G.; Bice, J.S.; Baxter, G.F. Pre- and postconditioning the heart with hydrogen sulfide $\left(\mathrm{H}_{2} \mathrm{~S}\right)$ against ischemia/reperfusion injury in vivo: A systematic review and meta-analysis. Basic Res. Cardiol. 2017, 113, 6. [CrossRef] [PubMed]

34. Caliendo, G.; Cirino, G.; Santagada, V.; Wallace, J.L. Synthesis and Biological Effects of Hydrogen Sulfide $\left(\mathrm{H}_{2} \mathrm{~S}\right)$ : Development of $\mathrm{H}_{2}$ S-Releasing Drugs as Pharmaceuticals. J. Med. Chem. 2010, 53, 6275-6286. [CrossRef] [PubMed]

35. Wang, R. Physiological Implications of Hydrogen Sulfide: A Whiff Exploration That Blossomed. Physiol. Rev. 2012, 92, 791-896. [CrossRef]

36. Rose, P.; Dymock, B.W.; Moore, P.K. GYY4137, a Novel Water-Soluble, $\mathrm{H}_{2}$ S-Releasing Molecule; Elsevier: Amsterdam, The Netherlands, 2015; Volume 554, pp. 143-167.

37. Kruithof, P.D.; Lunev, S.; Lozano, S.P.A.; Batista, F.D.A.; Al-Dahmani, Z.M.; Joles, J.A.; Dolga, A.M.; Groves, M.R.; van Goor, H. Unraveling the role of thiosulfate sulfurtransferase in metabolic diseases. Biochim. Biophys. Acta BBA Mol. Basis Dis. 2020, 1866, 165716. [CrossRef] [PubMed]

38. Kang, J.; Li, Z.; Organ, C.L.; Park, C.M.; Yang, C.T.; Pacheco, A.; Wang, D.; Lefer, D.J.; Xian, M. PH-Controlled Hydrogen Sulfide Release for Myocardial Ischemia-Reperfusion Injury. J. Am. Chem. Soc. 2016, 138, 6336-6339. [CrossRef]

39. Dyson, A.; Dal-Pizzol, F.; Sabbatini, G.; Lach, A.B.; Galfo, F.; Cardoso, J.D.S.; Mendonça, B.P.; Hargreaves, I.; Pinto, B.B.; Bromage, D.I.; et al. Ammonium tetrathiomolybdate following ischemia/reperfusion injury: Chemistry, pharmacology, and impact of a new class of sulfide donor in preclinical injury models. PLoS Med. 2017, 14, e1002310. [CrossRef]

40. Buckberg, G.D. Controlled reperfusion after ischemia may be the unifying recovery denominator. J. Thorac. Cardiovasc. Surg. 2010, 140, 12-18. [CrossRef]

41. Lelovas, P.P.; Kostomitsopoulos, N.; Xanthos, T.T. A Comparative Anatomic and Physiologic Overview of the Porcine Heart. J. Am. Assoc. Lab. Anim. Sci. 2014, 53, 432-438. 
42. Wang, F.; Keimig, T.; He, Q.; Ding, J.; Zhang, Z.; Pourabdollah-Nejad, S.; Yang, X.-P. Augmented healing process in female mice with acute myocardial infarction. Gend. Med. 2007, 4, 230-247. [CrossRef]

43. Johnson, M.S.; Moore, R.L.; Brown, D.A. Sex differences in myocardial infarct size are abolished by sarcolemmal KATP channel blockade in rat. Am. J. Physiol. Circ. Physiol. 2006, 290, H2644-H2647. [CrossRef]

44. Moher, D.; Liberati, A.; Tetzlaff, J.; Altman, D.G.; The PRISMA Group. Preferred reporting items for systematic reviews and meta-analyses: The PRISMA statement. PLoS Med. 2009, 6. [CrossRef]

45. Thomas, J.; Kneale, D.; McKenzie, J.E.; Brennan, S.E.; Bhaumik, S. Determining the Scope of the Review and the Questions It Will Address; Wiley Online Library: Hoboken, NJ, USA, 2019; Cochrane Handbook for Systematic Reviews of Interventions.

46. Hooijmans, C.R.; Rovers, M.M.; De Vries, R.B.M.; Leenaars, M.; Ritskes-Hoitinga, M.; Langendam, M.W. SYRCLE's risk of bias tool for animal studies. BMC Med. Res. Methodol. 2014, 14, 43. [CrossRef] [PubMed] 